\title{
Return-to-Work Policies and Labor Supply in Disability Insurance Programs*
}

\author{
By Arezou Zaresani ${ }^{\dagger}$
}

Disability Insurance (DI) programs are among the largest social assistance programs in developed countries. These programs provide benefits to individuals with health conditions that limit the amount or type of paid work they can perform. There have been concerns about the high levels of expenditure on DI programs. DI programs also have been criticized for inducing beneficiaries to reduce their labor supply. Most countries therefore have already implemented -or are considering implementing- policies to make their beneficiaries "return to work." These programs allow DI beneficiaries to collect all or a portion of their benefit while working. Although return-to-work policies intend to increase the labor supply in DI programs, the empirical evidence on the effectiveness of such policies is mixed. For example, Hoynes and Moffitt (1999); Benitez-Silva et al. (2011); Weathers II and Hemmeter (2011); and Bütler et al. (2015) find no effects of financial incentives to work in the US and Switzerland. However, Campolieti and Riddell (2012); Kostol and Mogstad (2014); and Ruh and Staubli (2016) find positive responses in Canada, Norway and Austria. Zaresani (2017) suggests that the relative size of the incentives to work induced by a program versus the adjustment costs that individuals face when changing their labor supply could possibly explain

* Discussant: Nicole Maestas, Associate Professor, Harvard University.

$\dagger$ Research Fellow, Melbourne Institute of Applied Economic and Social Research, 111 Barry Street, Faculty of Business and Economics, Level 5, University of Melbourne, Carlton, Victoria, Australia, a.zaresani@gmail.com. This study uses data provided by Alberta Human Services. The interpretation and conclusions contained herein are mine and do not necessarily represent the views of the Government of Alberta. I am grateful to Herb Emery, Stefan Staubli, Pamela Campa, Arvind Magesan, Patrick Button and Miguel Olivo-Villabrille for their help throughout this project. these disparate findings.

In this paper, I investigate whether a large increase in incentives to work in a return-to-work setting could induce DI recipients to increase their labor supply. I explore a policy change in a DI program called "Assured Income for the Severely Handicapped" (AISH) program in Canada using a Regression Discontinuity Design (RDD).

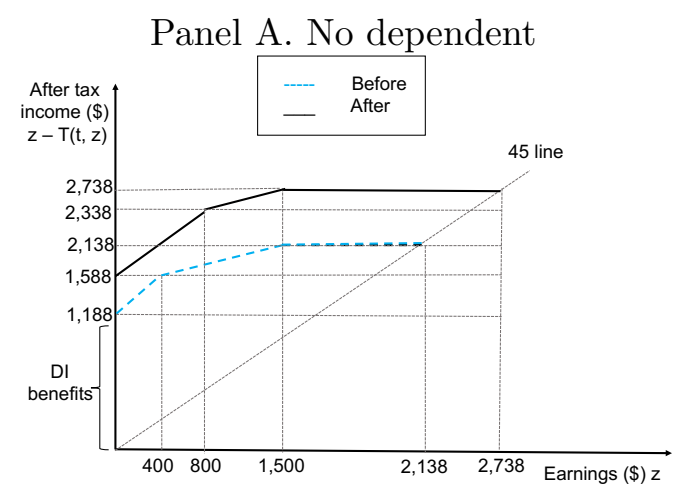

Panel B. With dependent

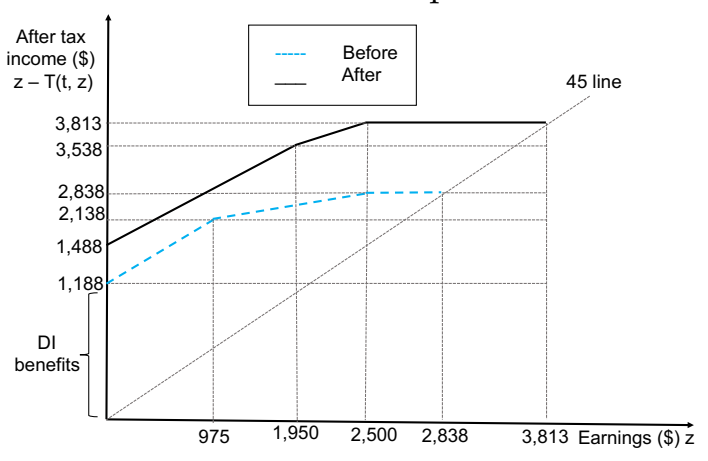

Figure 1. : Budget constraint of beneficiaries before and after the policy change.

\section{Institutional background}

AISH is the provincial DI program in Alberta in Canada. The benefits includes 
monthly DI benefits and some other supplementary benefits (i.e health insurance and child care). Furthermore, beneficiaries can work and still collect a portion of their DI benefits. The earning below an exemption threshold do not affect the benefits. But earnings above the threshold are subject to a $50 \%$ marginal tax rate (they loose $\$ 1$ of their monthly allowance for every $\$ 2$ accumulated above the exemption threshold). The policy change doubled the monthly exemption threshold of DI recipients and increased their monthly DI benefits by $35 \%$ effective from April 2012. The monthly exemption threshold was increased from $\mathrm{C} \$ 400$ to $\mathrm{C} \$ 800$ ( $\mathrm{C} \$ 975$ to $\mathrm{C} \$ 1,950$ ) for beneficiaries with no dependants (with dependants). The monthly DI benefits was increased to $\mathrm{C} \$ 1,588$ from $\mathrm{C} \$ 1,188$. Figure 1 illustrates the budget constraints of the beneficiaries before and after the policy change. This policy change is comparable to a drastic decrease in the marginal tax rate on earnings, providing much greater incentives to work for DI recipients.

\section{Data}

I use administrative dataset on monthly earnings and benefits of the AISH benefit recipients, obtained from the Government of Alberta. The data also has information on beneficiaries' individual characteristics including sex, age, marital status, family size, age DI awarded at, location of residence and the ICD-9 codes indicating type of disability. I focus on beneficiaries with non-physical disabilities, since it is believed that they are the marginal entrants to DI programs and are expected to be more responsive to the incentives to work. My study sample includes 18-64 years old individuals with non-physical disabilities. I select a time frame within two years of the policy change in AISH in March 2012: from March 2010 to April 2014.

\section{Empirical analysis}

\section{A. Regression Discontinuity Design (RDD)}

I investigate the effect of return-to-work policies on labor supply of DI beneficiaries using a sharp discontinuity in the induced incentives to work at the month of the policy change in the AISH program. I implement a RDD by estimating a regression of the form 1

$$
y_{i m}=\alpha+f(m)+\rho D_{m}+\beta X_{i t}+\epsilon_{i m}
$$

where $y_{i m}$ denotes the labor supply of individual $i$ in month $m$. I use real monthly earnings and Labor Force Participation (LFP) as outcome variables. The LFP is defined as a dummy that switches on when I observe positive earnings. $X_{i t}$ is a set of individual characteristics including sex, age, marital status, family size, age DI awarded at, location of residence and type of disability (psychotic, neurological, or mental). $D_{m}$ is the treatment dummy that captures the effects of the policy change by switching on for months following the policy change. $\epsilon_{i m}$ is the error term. $f($.$) denotes a poly-$ nomial time trend to control for time series variation in labor supply that would have occurred in absence of the policy change. The coefficient of interest is $\rho$ which captures the effect of the policy change on the labor supply.

The intuition behind my identification strategy is straightforward. I compare the labor supply outcomes right after the policy change (treatment group) to those right before the policy change (control group). The key identification assumption is that the only reason for change in individuals' labor supply is the policy change itself. In other words, there are not other variables that change discontinuously at the same time of the policy change in AISH. I isolate the change in labor supply solely due to the policy change by controlling for trend in labor supply from other sources using $f(m)$. This approach will not be threatened if other unobservable variables affecting labor supply change smoothly in the neighborhood of the policy change date (Hahn et al. 2001).

However, there are reasons to believe that the identification assumption might be violated. First, new entrants to the program

\footnotetext{
${ }^{1} \mathrm{RD}$ based on a time-series discontinuity is discussed by Hausman and Rapson (2017) and is similar to that used by Davis (2008) and Chen and Whalley (2012).
} 
after the policy change might be relatively healthier than those who entered before the policy change, and these new entrants can potentially work more. This is because the new policy allows beneficiaries to work more while collecting DI benefits. Second, there might be anticipatory effects since the policy change was announced two months before it was implemented. To deal with these concerns, I follow a similar approach to that of Marie and Vall Castello (2012) and exclude those who have entered into the program after the policy change was announced in February 2012.

\section{B. Graphical evidence}

Figure 2 plots the trends in labor supply outcomes; the mean real earning $\$^{2}$ and the LFP within one year of the policy change. The fitted lines before and after the policy change are also illustrated. This figure suggests that first, there is a discontinuous increase in both earnings and LFP around the date of the policy change. Second, the trends in earnings and LFP both before and after the policy change are linear. I therefore use a linear time trend $f(m)$ in (1).

Panel A. Monthly earnings.

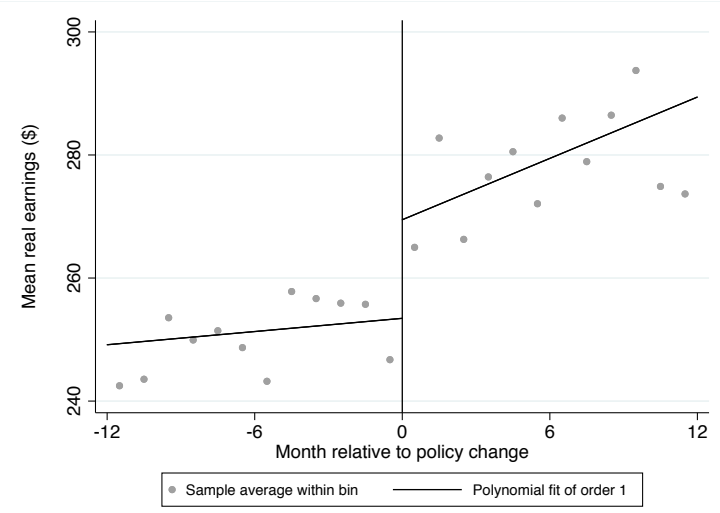

\footnotetext{
${ }^{2}$ The nominal earnings are adjusted for inflation using the CPI, with March 2012 as base.
}

Panel B. Labor Force Participation.

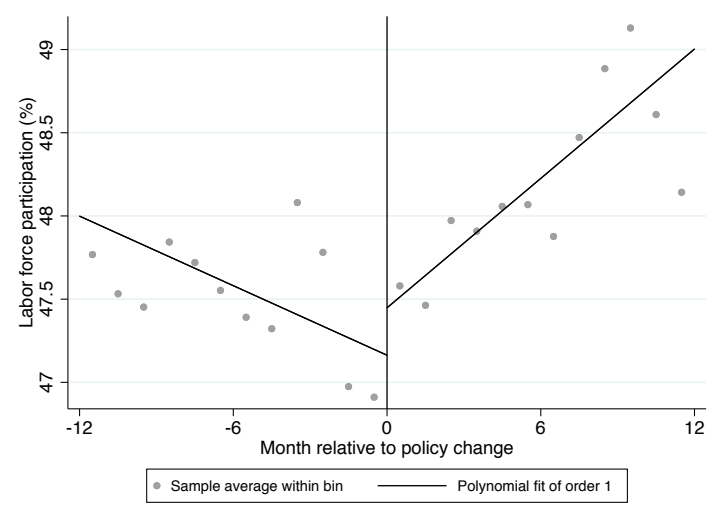

Figure 2. : Discontinuty in labor supply before and after the policy change.

\section{RDD estimates}

Table 1 presents the estimated effects on the labor supply from the increase in the incentives to work induced by the policy change. I use Calonico et al. (2014) to non-parametrically construct confidence intervals around the estimated average treatment effects using (1). My main specification is a local linear model with a triangular kernel density (which imposes more weight on observations in months closer to the time of the policy change) within six months of the policy change (i.e. six months bandwidth). The estimated effect of the policy change is a statistically significant 8.9 percent increase in the real average monthly earnings and about one percentage point increase in the LFP (although not significant at conventional levels). Adding individual covariates including sex, age, marital status, family size, age DI awarded at, location of residence and disability type do not change the estimates. I also estimate the effects using bandwidths varying from 3 to 12 months. The estimates are quite robust to the selected bandwidth. 
Table 1-: Estimated effects of the policy change on labor supply.

Panel A. Monthly earnings $(\mathrm{C} \$)$.

\begin{tabular}{lcc}
\hline \hline & $(1)$ & $(2)$ \\
\hline Estimated & $22.52^{* * *}$ & $22.54^{* * *}$ \\
effect & $(6.88)$ & $(6.86)$ \\
\hline Mean before & 252.69 & 252.69 \\
policy change & $(427.04)$ & $(427.04)$ \\
& & \\
Individual & No & Yes \\
co-variates & & \\
\hline Num. of Obs. & 112,768 & 112,768 \\
\hline \hline
\end{tabular}

Panel B. Labor Force Participation (percent).

\begin{tabular}{lcc}
\hline \hline & $(1)$ & $(2)$ \\
\hline $\begin{array}{l}\text { Estimated } \\
\text { effect }\end{array}$ & 0.99 & 1.06 \\
\hline $\begin{array}{l}\text { Mean before } \\
\text { policy change }\end{array}$ & 47.41 & $(0.76)$ \\
$\begin{array}{l}\text { Individual } \\
\text { co-variates }\end{array}$ & No & Yes \\
\hline Num. of Obs. & 112,768 & 112,768 \\
\hline \hline
\end{tabular}

Note: Individual covariates includes sex, age, marital status, family size, age DI awarded at, location of residence and type of disability (psychotic, neurological, or mental). The robust standard errors in the parenthesis are clustered at the individual level and are estimated using Calonico et al. (2014).

$* p<0.10, * * p<0.05, * * * p<0.01$

\section{Seasonality in the labor market}

The estimates suggest that the increase in incentives to work induced by the policy change in April 2012 caused an increase in the labor supply of the beneficiaries. However, there are a concerns that the seasonality of the labor market might be the driving force. To shed light on this concern, I also estimate the effects of placebo policy changes in April 2010, April 2011, and April 2013.
Table 2-: Estimated effects from placebo policy changes.

Panel A. Placebo policy change in April 2010.

\begin{tabular}{lcc}
\hline \hline & 2010. & \\
& $\begin{array}{c}\text { Earnings } \\
\text { (dollar) }\end{array}$ & $\begin{array}{c}\text { LFP } \\
\text { (percent) }\end{array}$ \\
\hline Estimated & -8.06 & -0.08 \\
effect & $(6.51)$ & $(0.78)$ \\
\hline Mean before & 271.95 & 52.08 \\
policy change & $(422.86)$ & \\
Num. of Obs. & 99,575 & 99,575 \\
\hline \hline
\end{tabular}

Panel B. Placebo policy change in April

\begin{tabular}{lcc} 
& 2011. & \\
\hline \hline & $\begin{array}{c}\text { Earnings } \\
\text { (dollar) }\end{array}$ & $\begin{array}{c}\text { LFP } \\
\text { (percent) }\end{array}$ \\
\hline Estimated & -2.84 & -0.20 \\
effect & $(6.22)$ & $(0.75)$ \\
\hline Mean before & 249.92 & 47.82 \\
policy change & $(422.86)$ & \\
Num. of Obs. & 107,476 & 107,476 \\
\hline \hline
\end{tabular}

Panel C. Placebo policy change in April

\begin{tabular}{lcc} 
& 2013. & \\
\hline \hline & $\begin{array}{c}\text { Earnings } \\
\text { (dollar) }\end{array}$ & $\begin{array}{c}\text { LFP } \\
\text { (percent) }\end{array}$ \\
\hline $\begin{array}{l}\text { Estimated } \\
\text { effect }\end{array}$ & -0.85 & 0.02 \\
Mean before & $281.65)$ & $(0.72)$ \\
policy change & $(472.67)$ & 47.92 \\
Num. of Obs. & 118,886 & 118,886 \\
\hline \hline
\end{tabular}

Note: The effects are estimated using a six-month window of the corresponding placebo policy change. Individual covariates are included in all the estimates. The robust standard errors in parenthesis are clustered in individual level and are estimated using Calonico et al. (2014).

$* p<0.10, * * p<0.05, * * * p<0.01$

Table 2 presents the estimates within a six-month window of the corresponding placebo policy change. All the estimates are negative and insignificant at conventional levels. This suggests that if there is seasonality in the labor market, the estimates presented in Table 1 represent the lower bound on the effects on the labor supply from the increase in incentives to work. 


\section{Conclusion}

Findings on the effectiveness of returnto-work policies in DI programs are mixed. Zaresani (2017) shows that the size of the barriers that individuals face when changing their labor supply, versus the induced incentives to work by a policy change might explain the disparate findings. In this paper, I evaluate the effect of a policy change in a DI program that provides large incentives to work. My findings from a RDD model that explores the discontinuity in incentives to work induced by a policy change in AISH program confirms the findings of Zaresani (2017). These results have important implications for designing policies to increase labor supply in DI programs.

\section{REFERENCES}

Benitez-Silva, Hugo, Moshe Buchinsky, and John Rust, "Induced Entry Effects of a $\$ 1$ for $\$ 2$ Offset in SSDI Benefits," 2011.

Bütler, Monika, Eva Deuchert, Michael Lechner, Stefan Staubli, and Petra Thiemann, "Financial work incentives for disability benefit recipients : Lessons from a randomized field experiment," IZA Journal of Labor Policy, 2015, 4 (18).

Calonico, Sebastian, Matias D. Cattaneo, and Rocio Titiunik, "Robust nonparametric confidence intervals for regression-discontinuity designs," Econometrica, 2014, 82 (6), 2295-2326.

Campolieti, Michele and Chris Riddell, "Disability policy and the labor market: Evidence from a natural experiment in Canada, 1998-2006," Journal of Public Economics, apr 2012, 96 (3-4), 306-316.

Chen, Yihsu and Alexander Whalley, "Green Infrastructure: The Effects of Urban Rail Transit on Air Quality," American Economic Journal: Economic Policy, 2012, 4 (1), 58-97.
Davis, LucasW., "The Effect of Driving Restrictions on Air Quality in Mexico City," Journal of Political Economy, 2008, 116 (1), 38-81.

Hahn, Jinyong, Petra Todd, and Wilbert Van der Klaauw, "Identification and Estimation of Treatment Effects with a Regression-Discontinuity Design," Econometrica, 2001, 69 (1), 201-209.

Hausman, Catherine and David Rapson, "Regression Discontinuity in Time: Considerations for Empirical Applications," NBER Working Paper, 2017.

Hoynes, Hillary W. and Robert Moffitt, "Tax Rates and Work Incentives in the Social Security Disability Insurance Program: Current Law and Alternative Reforms," National Tax Journal, 1999, 52 (4), 623-654.

Kostol, Andreas Ravndal and Magne Mogstad, "How Financial Incentives Induce Disability Insurance Recipients to Return to Work," American Economic Review, 2014, 104 (2), 624-655.

Marie, Olivier and Judit Vall Castello, "Measuring the (income) effect of disability insurance generosity on labour market participation," Journal of Public Economics, feb 2012, 96 (1-2), 198-210.

Ruh, Philippe and Stefan Staubli, "Financial Incentives and Earnings of Disability Insurance Recipients: Evidence from a Notch Design," 2016.

Weathers II, Robert R and Jeffrey Hemmeter, "The Impact of Changing Financial Work Incentives on the Earnings of Social Security Disability Insurance (SSDI) Beneficiaries," Public Policy Analysis and Management, 2011, 30 (4), 708-728.

Zaresani, Arezou, "Adjustment Costs and Incentives to Work: Evidence from a Disability Insurance Program," 2017. 